\title{
Response of finger circulation to energy equivalent combinations of magnitude and duration of vibration
}

\author{
M Bovenzi, C J Lindsell, M J Griffin
}

\begin{abstract}
Objectives-To investigate the acute response of finger circulation to vibration with different combinations of magnitude and duration but with the same "energy equivalent" acceleration magnitude according to current standards for hand transmitted vibration.
\end{abstract}

Methods-Finger skin temperature (FST) and finger blood flow (FBF) were measured in the middle fingers of both hands of 10 healthy men who had not used hand held vibrating tools regularly. With a static load of $10 \mathrm{~N}$, the right hand was exposed to $125 \mathrm{~Hz}$ vibration with the following unweighted root mean square (rms) acceleration magnitudes and durations of exposure: $44 \mathrm{~m} / \mathrm{s}^{2}$ for 30 minutes; $62 \mathrm{~m} / \mathrm{s}^{2}$ for 15 minutes; $88 \mathrm{~m} / \mathrm{s}^{2}$ for $7.5 \mathrm{~min}$ utes; $125 \mathrm{~m} / \mathrm{s}^{2}$ for 3.75 minutes; and 176 $\mathrm{m} / \mathrm{s}^{2}$ for 1.88 minutes. These vibration exposures produce the same 8 hour energy equivalent frequency weighted acceleration magnitude $\left(\sim 1.4 \mathrm{~m} / \mathrm{s}^{2} \mathrm{rms}\right)$ according to international standard ISO 5349 (1986). Finger circulation was measured in both the right (vibrated) and the left (nonvibrated) middle fingers before application of the vibration, and at fixed intervals during exposure to vibration and during a 45 minute recovery period.

Results-The FST did not change during exposure to vibration, whereas vibration with any combination of acceleration magnitude and duration produced significant percentage reductions in the FBF of the vibrated finger compared with the FBF before exposure (from $-40.1 \%(95 \%$ confidence interval $(95 \% \mathrm{CI})-24.3 \%$ to $-57.2 \%)$ to $-61.4 \%(95 \%$ CI $-45.0 \%$ to $-77.8 \%)$. The reduction in FBF during vibration was stronger in the vibrated finger than in the non-vibrated finger. Across the five experimental conditions, the various vibration stimuli caused a similar degree of vasoconstriction in the vibrated finger during exposure to vibration. There was a progressive decrease in the FBF of both fingers after the end of exposure to vibration with acceleration magnitudes of $44 \mathrm{~m} / \mathrm{s}^{2}$ for 30 minutes and $62 \mathrm{~m} / \mathrm{s}^{2}$ for 15 minutes. Significant vasoconstrictor after effects were not found in either finger after exposure to any of the other vibration stimuli with greater acceleration magnitudes for shorter durations.
Conclusions-For the range of vibration magnitudes investigated (44 to $176 \mathrm{~m} / \mathrm{s}^{2}$ rms unweighted; 5.5 to $22 \mathrm{~m} / \mathrm{s}^{2}$ rms when frequency weighted according to ISO 5349), the vasoconstriction during exposure to $125 \mathrm{~Hz}$ vibration was independent of vibration magnitude. The after effect of vibration was different for stimuli with the same energy equivalent acceleration, with greater effects after longer durations of exposure. The energy equivalent acceleration therefore failed to predict the acute effects of vibration both during and after exposure to vibration. Both central and local vasoregulatory mechanisms are likely to be involved in the response of finger circulation to acute exposures to 125 Hz vibration.

(Occup Environ Med 2001;58:185-193)

Keywords: finger circulation; energy equivalent acceleration magnitude; vibration frequency, magnitude, and duration

The adverse effects of hand transmitted vibration on the finger circulation of workers who use vibrating tools are thought to depend primarily on the physical characteristics of vibration, mainly its frequency and its magnitude, as well as on the duration of vibration. ${ }^{1}$ Our previous experimental studies have shown that the vasoconstrictor response of the digital vessels after exposure to vibration with a frequency of $125 \mathrm{~Hz}$ increased with either an increase of the root mean square (rms) acceleration magnitude from 5.5 to $62 \mathrm{~m} / \mathrm{s}^{2}$ (with an unchanged duration of exposure of 15 minutes) or with an increase in the duration of exposure from 7.5 to 30 minutes (with an unchanged vibration magnitude of $87 \mathrm{~m} / \mathrm{s}^{2}$ $\mathrm{rms}) .{ }^{2}$ We also found an effect of the frequency of vibration on digital circulatory function: with the same frequency weighted acceleration, acute exposures to vibration with frequencies from 31.5 to $250 \mathrm{~Hz}$ provoked a greater reduction in finger blood flow (FBF) than did vibration of $16 \mathrm{~Hz} .{ }^{4}$ Moreover, the higher the frequency of vibration, the stronger the decrease in FBF during the recovery period after the end of the vibration. This finding does not seem to corroborate the frequency weighting for vibration recommended in international standard ISO 5349 (1986), which assumes that the response of the hand-arm system to vibration is independent of the vibration frequency 
below $16 \mathrm{~Hz}$ but reduces in inverse proportion to the vibration frequency at higher frequencies. $^{5}$

In current standards for hand transmitted vibration, daily exposure to vibration is expressed as 8 hour energy equivalent frequency weighted rms acceleration $(\mathrm{A}(8))$, a measure of vibration which assumes an inverse relation between daily duration of exposure and the square of the frequency weighted acceleration magnitude of the vibration. ${ }^{6}$ This second power time dependency is convenient for instrumentation and measurement procedures and is commonly assumed in rms averaging methods. Nevertheless, there is a shortage of both epidemiological and experimental data to establish that such an energy equivalent time dependency reflects the response of the hand-arm system to vibration of different daily durations.

The aim of this study was to investigate the acute response of finger circulation to vibration with different combinations of magnitude and duration but with the same energy equivalent acceleration magnitude according to current standards for hand transmitted vibration. ${ }^{56}$ The vibration was delivered at a frequency of $125 \mathrm{~Hz}$ because this vibration frequency is widely thought to cause vibration induced white finger. ${ }^{7}$ Moreover, several experimental investigations have shown that $125 \mathrm{~Hz}$ induces greater changes in finger circulation than some lower and higher vibration frequencies. ${ }^{89}$ The circulatory effects of vibration were monitored in both vibrated and non-vibrated fingers.

\section{Subjects and methods}

SUBJECTS

Ten healthy male volunteers, eight white and two oriental, gave written, informed consent to participate in the investigation. All subjects were students or office workers with no history of regular use of hand held vibrating tools in occupational or leisure activities. All subjects were non-smokers. None of them reported cardiovascular or neurological disorders, connective tissue diseases, injuries to the upper limbs, or a family history of Raynaud's phenomenon. The mean (SD) age of the subjects was 30.6 (8.5) years, their mean (SD) height was $179(5.3) \mathrm{cm}$, and their mean (SD) weight was $80(12.2) \mathrm{kg}$. Finger dimensions were measured with Vernier callipers to a precision of $0.5 \mathrm{~mm}$. Finger volume and surface area were calculated from that of a cylinder formed from an ellipse based on the dimensions of the proximal interphalangeal joint and the length of the finger. The mean (SD) volume of the middle right finger was 25.1 (3.6) $\mathrm{cm}^{3}$ and that of the middle left finger was $23.8(3.3) \mathrm{cm}^{3}$. The mean (SD) surface areas were 99.9 (10.3) $\mathrm{cm}^{2}$ and $96.5(10.3) \mathrm{cm}^{2}$ for the middle right and the middle left finger, respectively.

MEASURES OF FINGER CIRCULATION

Finger blood flow and finger systolic blood pressure (FSBP) were measured in the middle fingers of both the right and the left hand. Mercury in silastic strain gauges were placed around the distal phalanx at the base of the nails and plastic pressure cuffs for air inflation $(2.4 \times 9 \mathrm{~cm})$ were fixed around the proximal phalanges and secured with a Velcro strip (fig 1 ). The pressure cuffs and strain gauges were connected to a plethysmograph (Digitmatic DM2000, Medimatic A/S, Copenhagen).

The FBF was measured with a venous occlusion technique: the pressure cuffs were inflated to a pressure of $40-60 \mathrm{~mm} \mathrm{Hg}$ and the rise of volume was detected by the strain gauge according to the criteria given by Greenfield et al. ${ }^{10}$ Three plethysmographic recordings of $\mathrm{FBF}$ were made for each measurement, and the mean value was calculated. The FBF measurements were expressed as $\mathrm{ml} / 100 \mathrm{ml} / \mathrm{min}$.

The FSBP was measured with the technique described by Nielsen et al. ${ }^{11}$ The tips of the middle fingers were squeezed and the pressure cuffs inflated to a suprasystolic pressure greater than $200 \mathrm{~mm} \mathrm{Hg}$. The pressure in the cuffs were then reduced at about $3 \mathrm{~mm} \mathrm{Hg} / \mathrm{s}$. The FSBP was defined as the cuff pressure at which a volume increase was detected in the distal phalanx by means of the strain gauge.

Brachial systolic and diastolic blood pressures were measured in the upper right arm by an auscultatory technique with a standard rubber cuff $(12 \times 23 \mathrm{~cm})$.

Finger skin temperature (FST) was measured with $\mathrm{k}$ type thermocouples connected to an HVLab thermal aesthesiometer to measure temperatures with an accuracy of $\pm 0.2^{\circ} \mathrm{C}$. The thermocouples were taped to the dorsal surface of the medial phalanges of the middle fingers with porous surgical tape (fig 1).

The room temperature was measured by a mercury in glass thermometer.

\section{EXPERIMENTAL PROCEDURE}

The experiment was performed in a room with a mean (SD) temperature of $24.4(0.8)^{\circ} \mathrm{C}$. Subjects were requested to avoid caffeine consumption for 2 hours and alcohol for 12 hours before testing.

The subjects lay supine throughout the investigation with their hands resting on wooden platforms alongside the body at about the level of the heart. After a period of acclimatisation of about 15 minutes, FBF and FST were measured in the middle fingers of both hands. After the pre-exposure measurements had been obtained, the subjects were asked to apply a downward force of $10 \mathrm{~N}$ with their right hand on a horizontal wooden platform that was mounted on an electrodynamic vibrator (VP30, Derritron). The signal from a Kulite force cell mounted between the platform and the shaker was used to provide visual feedback for the control of downward force. All five digits of the right hand were in contact with the wooden platform. The arrangement for controlling contact force and for generating and monitoring the vibration is illustrated in figure 1 and has been described elsewhere. ${ }^{12}$

Sinusoidal vibration at $125 \mathrm{~Hz}$ was produced in the vertical direction with one of the combinations of unweighted rms acceleration magnitude and duration shown in table 1. The unweighted rms acceleration magnitudes and durations of vibration were chosen to produce 


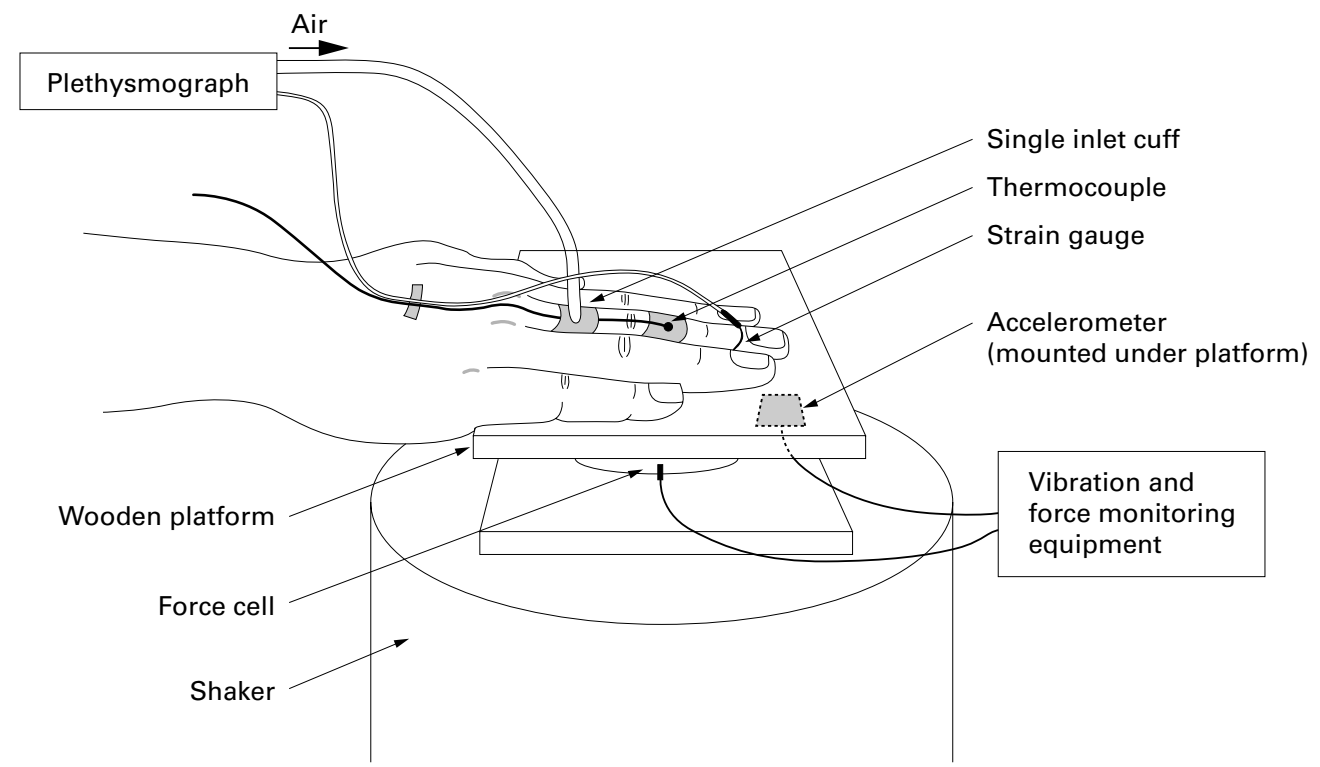

Figure 1 Experimental set up for generating the vibration, controlling the contact force, and measuring finger circulation.

the same $\mathrm{A}(8)$ value $\left(\simeq 1.4 \mathrm{~m} / \mathrm{s}^{2} \mathrm{rms}\right)$ according to international standard ISO 5349 (1986). ${ }^{5}$ The exposure-response relation included in an annex to ISO 5349 predicts that vibration induced white finger is expected to occur in $10 \%$ of a worker population after about 15 years of daily exposure to the $\mathrm{A}(8)$ value used in this study.

The measurements of FBF and FST were made in both the exposed (right) and unexposed (left) middle fingers immediately before exposure to vibration, throughout the period of exposure to vibration, and for 45 minutes after exposure. For the 30 minute period of vibration, measures of finger circulation were obtained at $0.5,1.5,3.5,5.5,7.5,15,22.5$, and 30 minutes after the start of vibration. The first six of these measures were taken during the 15 minute exposure, the first four during the 7.5 minute exposure, the first three during the 3.75 minute exposure, and the first two during the 1.88 minute exposure. Measurements were taken at the same intervals after the end of vibration and then at 7.5 minute intervals during the rest of the recovery period.

Finger and brachial blood pressures were measured at the beginning and at the end of each experimental session.

Previous studies have shown that the measures of finger circulation (FST and FBF) do not change when the static force used in this experiment is applied without vibration. ${ }^{2412}$ For this reason, the present study did not include static measures.

Table 1 Conditions of exposure to vibration used in the study (the different combinations of root mean square (rms) acceleration magnitude and duration of exposure to a vibration with a frequency of $125 \mathrm{~Hz}$ produce the same 8 hour energy equivalent frequency weighted acceleration magnitude as calculated by the international standard ISO 5349 (1986))

\begin{tabular}{llll}
\hline $\begin{array}{l}\text { Unweighted acceleration } \\
\text { magnitude }\left(\mathrm{m} / \mathrm{s}^{2}, \text { rms }\right)\end{array}$ & $\begin{array}{l}\text { Frequency weighted } \\
\text { acceleration magnitude } \\
\left(\mathrm{m} / \mathrm{s}^{2}, \text { rms }\right)\end{array}$ & $\begin{array}{l}\text { Exposure duration } \\
(\text { min })\end{array}$ & $\begin{array}{l}8 \text { Hour energy equivalent } \\
\text { frequency weighted acceleration } \\
\text { magnitude }\left(\mathrm{m} / \mathrm{s}^{2}, \text { rms }\right)\end{array}$ \\
\hline 44 & 5.5 & 30 & 1.4 \\
62 & 7.75 & 15 & 1.4 \\
88 & 11.0 & 7.5 & 1.4 \\
125 & 15.6 & 3.75 & 1.4 \\
176 & 22.0 & 1.88 & 1.4 \\
\hline
\end{tabular}

The 10 subjects were divided into two equal groups, so that within each group the five experimental conditions could be presented in a balanced order. Each subject attended five separate experimental sessions, lasting from about 1 to 1.5 hours, each held on a separate day. All sessions were completed within a 3 week period.

The study was approved by the human experimentation safety and ethics committee of the Institute of Sound and Vibration Research at the University of Southampton (UK).

\section{STATISTICAL METHODS}

Data analysis was performed with the software package Stata (version 6.0). The data were summarised with the mean as a measure of central tendency and the SD, the SEM, or the $95 \%$ confidence interval $(95 \% \mathrm{CI})$ as measures of dispersion. The difference between paired means was tested by Student's $t$ test.

Repeated measures analysis of variance (ANOVA) was used to test the hypothesis of no difference in the vascular responses under different exposure conditions (treatments). When the treatment by time interaction term in ANOVA was found to be significant $(p<0.05)$, a separate analysis of the results within treatments was made. To control for the effect of covariates on the response variables, repeated measures analysis of covariance (ANCOVA) was also used. When the compound symmetry assumption (the measures have the same variance and the correlations between each pair of repeated measures are equal) was violated, a conservative test of the repeated measures factor was used by reducing the degrees of freedom of the $F$ ratio (GreenhouseGeisser method). ${ }^{13}$ The Bonferroni 95\% CIs for pairwise mean comparisons of the response by time were used when the probability value for the $F$ test of repeated measures ANOVA was $<0.05$ (two sided).

The relation between continuous variables with repeated measures was assessed by the 

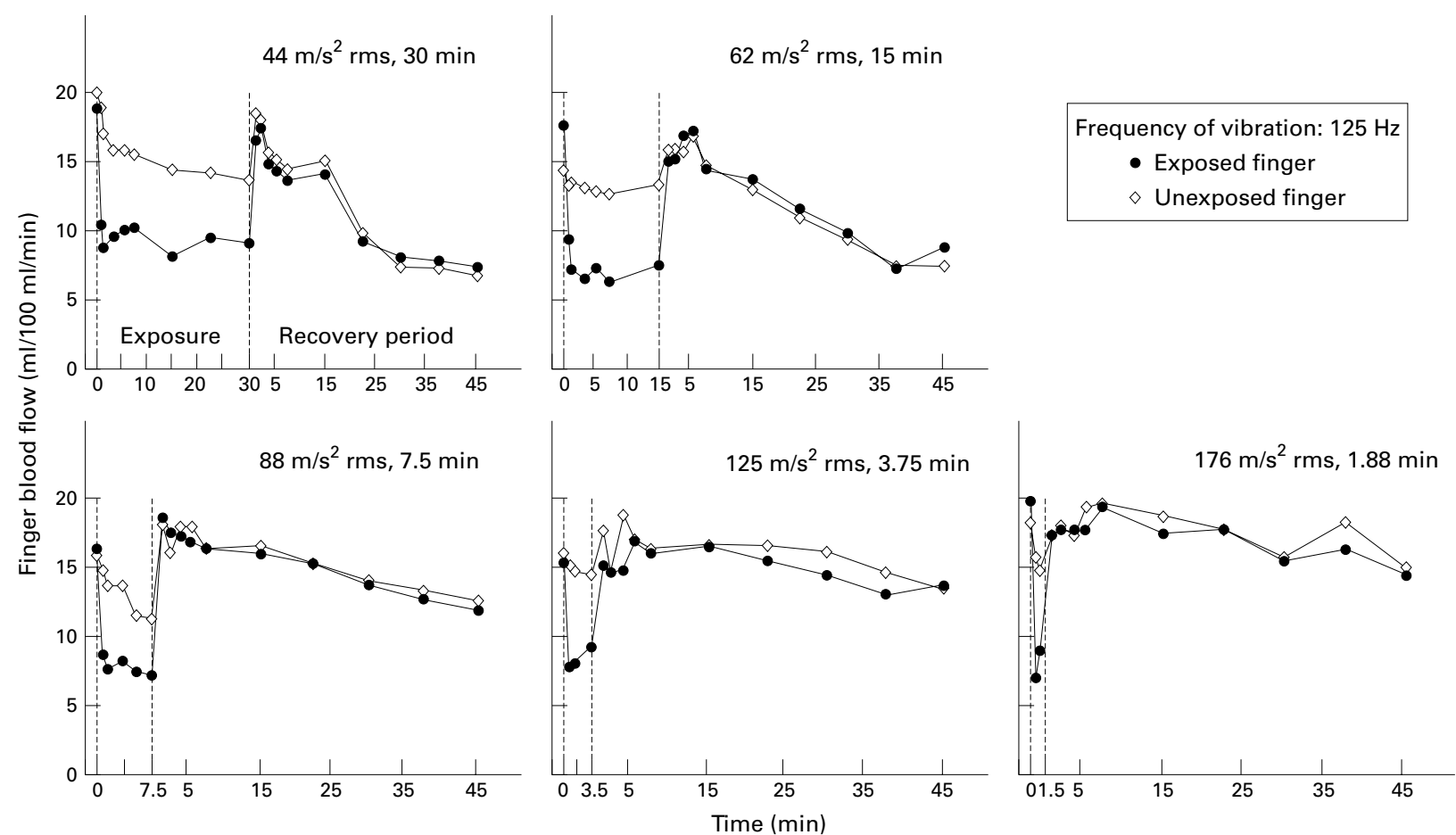

Figure 2 Mean values of finger blood flow measured in 10 healthy men before, during, and after exposures to vibration with different combinations of acceleration magnitude and duration but with the same 8 hour energy equivalent frequency weighted acceleration magnitude ( $\simeq 1.4$ m/s ${ }^{2}$ rms) according to current standards for hand transmitted vibration.

generalised estimating equations approach to repeated measures data sets to account for the correlation within subjects. ${ }^{14}$

\section{Results}

The vascular measurements taken before exposures to vibration showed no changes in the FBF, FST, or finger systolic blood pressure of either the exposed or the unexposed finger across the five experimental sessions. No differences in the pre-exposure measures of digital circulation were found between the middle right and middle left fingers within any session. Brachial systolic and diastolic arterial pressures measured before exposure did not change significantly within subjects across sessions (range of values across subjects and sessions: $100 / 60-135 / 80 \mathrm{~mm} \mathrm{Hg}$ ). No differences were found for finger or brachial arterial blood pressures measured at the beginning and the end of the five sessions.

Before exposure, analysis of repeated measures by the generalised estimating equations method showed that FBF was positively related to FST $(p<0.005)$ and finger volume $(p<0.05)$ in both the middle right and the middle left finger. The FBF and FST values in both fingers were inversely related to age $(p<0.05)$. The FSTs were not related to finger surface areas. For both fingers, the FBF and FST showed a positive, not significant, relation to room temperature $(p=0.07-0.12)$. In neither finger was there a significant relation between finger systolic blood pressure and either FBF or FST.

The air temperature in the laboratory was well controlled and the repeated measures ANOVA did not show any significant difference in the room temperature across the five experimental sessions, ranges of mean (SD) values being $23.8(1.0)-24.6(0.6)^{\circ} \mathrm{C}$.

FINGER SKIN TEMPERATURE

Before exposure, the mean (SD) values of FST varied from $30.8(2.8)$ to $32.3(2.1)^{\circ} \mathrm{C}$ in the right (exposed) finger and from 31.4 (2.7) to $33.0(1.4)^{\circ} \mathrm{C}$ in the left (unexposed) finger. Repeated measures ANCOVA showed neither treatment by time interaction nor differences in the FST between the five exposure conditions for either the vibrated or the non-vibrated finger during either the vibration or the recovery period (results not shown).

\section{FINGER BLOOD FLOW}

Figure 2 shows the mean values of FBF measured in both the middle right (exposed) and the middle left (unexposed) finger before, during, and after exposures to $125 \mathrm{~Hz}$ vibration with different combinations of magnitude and duration but with the same energy equivalent frequency weighted acceleration magnitude $\left(\mathrm{A}(8) \simeq 1.4 \mathrm{~m} / \mathrm{s}^{2} \mathrm{rms}\right)$. When data analysis was performed over the full period (before exposure, exposure, and recovery) of the five experimental sessions, repeated measures ANCOVA showed a significant treatment by time interaction for both fingers $(\mathrm{p}<0.001)$. Therefore, the analysis of the results was performed for each exposure condition separately. Age, finger volume, and room temperature were included as covariates in ANCOVA because they were predictive of FBF in both fingers before exposure. Tables 2 and 3 report the mean (SEM) values for FBF in the exposed and unexposed fingers throughout the various experimental sessions, respectively, as well as the mean $(95 \% \mathrm{CI})$ values for the percentage 


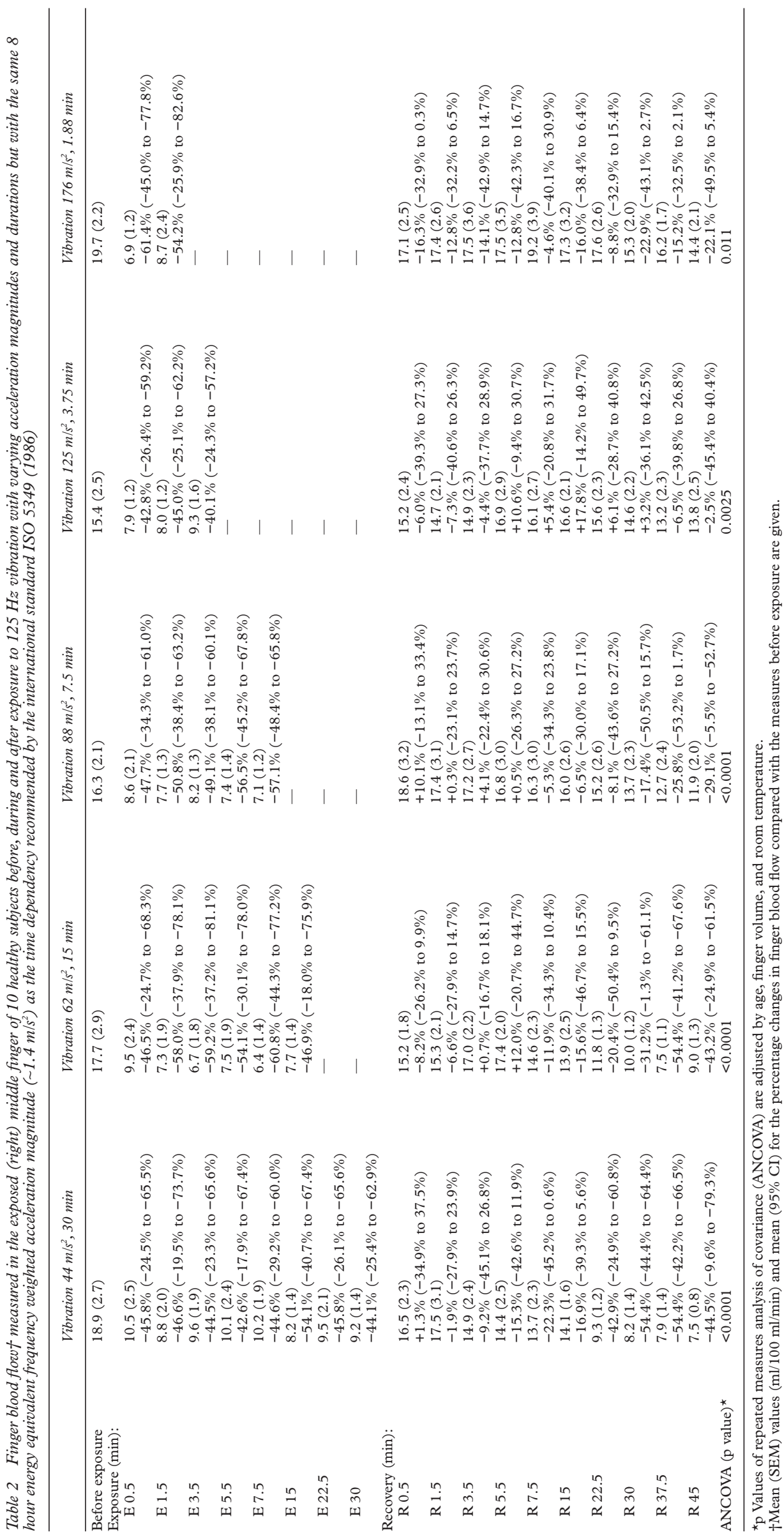

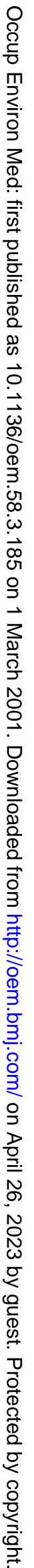



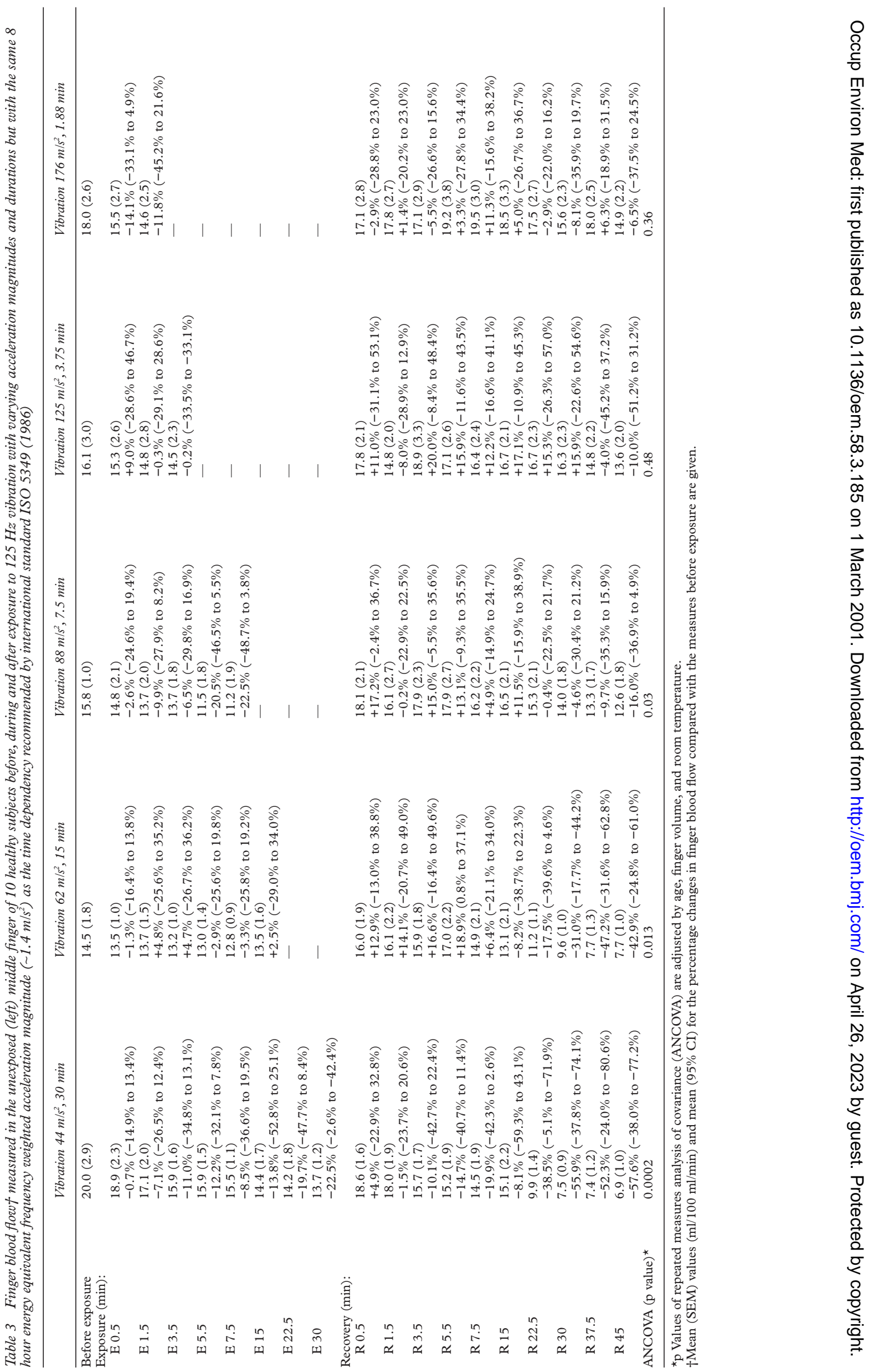
changes in FBF compared with the measures before exposure.

Acute exposure to $125 \mathrm{~Hz}$ vibration with any combination of acceleration magnitude and duration provoked a significant reduction of $\mathrm{FBF}$ in the right (vibrated) finger ( $\mathrm{p}$ values of repeated measures ANCOVA: 0.011 to $<0.0001$, table 2). Compared with the measurements before exposure, a reduction in the FBF of the vibrated finger was found at each measurement time during the exposure period for all experimental conditions. Within each exposure condition, there was no difference between the consecutive measurements of the $\mathrm{FBF}$ - that is, the decrease in blood flow in the vibrated finger did not change significantly throughout the various exposure periods. Across the five experimental conditions, the degree of vasoconstriction in the vibrated finger was similar at each measurement time during exposure to the various vibration stimuli.

Over the whole experimental period, exposure of the right hand to vibration with acceleration magnitudes of $44 \mathrm{~m} / \mathrm{s}^{2}$ for $30 \mathrm{~min}$ utes, $62 \mathrm{~m} / \mathrm{s}^{2}$ for 15 minutes, and $88 \mathrm{~m} / \mathrm{s}^{2}$ for 7.5 minutes caused an overall, significant, reduction of FBF in the left (non-vibrated) finger ( $\mathrm{p}$ values of repeated measures ANCOVA: 0.03 to 0.0002 ), whereas no significant changes were found during exposure to vibration with an acceleration magnitude of either $125 \mathrm{~m} / \mathrm{s}^{2}$ for 3.75 minutes or $176 \mathrm{~m} / \mathrm{s}^{2}$ for 1.88 minutes (table 3 ). Compared with the measurements before exposure, a decrease in the FBF of the left (non-vibrated) finger occurred after the 5th minute of exposure of the right hand to acceleration magnitudes of $44 \mathrm{~m} / \mathrm{s}^{2}$ for 30 minutes and $88 \mathrm{~m} / \mathrm{s}^{2}$ for 7.5 minutes.

At almost all measurement times during the different periods of exposure to vibration, the decrease in $\mathrm{FBF}$ was significantly greater in the vibrated finger than in the non-vibrated finger (paired $t$ test: $\mathrm{p}<0.05$ ). Only at the 5.5 and 7.5 minutes of exposure, no differences were found in the FBF between the right (exposed) and the left (unexposed) finger when the right hand was exposed to vibration with a magnitude of $88 \mathrm{~m} / \mathrm{s}^{2}$.

Immediately after vibration ended, there was an increase in the FBF of the right (vibrated) finger. This vasodilation was seen after exposure to vibration with all combinations of acceleration magnitude and duration; the immediate increase in FBF was significant when compared with the last measure of FBF taken during exposure to $125 \mathrm{~Hz}$ vibration with a magnitude of $44 \mathrm{~m} / \mathrm{s}^{2}$ for 30 minutes (mean $+93.3 \% ; 95 \%$ CI $47.8 \%$ to $139 \%), 62 \mathrm{~m} / \mathrm{s}^{2}$ for 15 minutes (mean $+153 \%$; $95 \%$ CI $58.3 \%$ to $246 \%$ ), $88 \mathrm{~m} / \mathrm{s}^{2}$ for 7.5 minutes (mean $+168 \%$; $95 \%$ CI $112 \%$ to $223 \%), 125 \mathrm{~m} / \mathrm{s}^{2}$ for 3.75 minutes (mean $+73.5 \%$; $95 \%$ CI $24.6 \%$ to $122 \%$ ), and $176 \mathrm{~m} / \mathrm{s}^{2}$ for 1.88 minutes (mean $+154 \%$; $95 \%$ CI $65.6 \%$ to 242 ). In the left (non-vibrated) finger, a significant increase in FBF occurred only after the end of exposure to vibration with an acceleration magnitude of either $44 \mathrm{~m} / \mathrm{s}^{2}$ for 30 minutes (mean $+44.3 \%$; $95 \%$ CI $11.9 \%$ to $76.7 \%$ ) or $88 \mathrm{~m} / \mathrm{s}^{2}$ for 7.5 minutes (mean $+93.6 \%$; $95 \%$ CI $24.4 \%$ to $163 \%)$. In either finger, there was no significant difference between the FBF measured before exposure and immediately after the end of any conditions of exposure.

When compared with the measures before exposure, a decrease in FBF during the recovery period was found in both the vibrated and the non-vibrated finger, about 22.5 minutes after the end of exposure to vibration with acceleration magnitude of either $44 \mathrm{~m} / \mathrm{s}^{2}$ for 30 minutes or $62 \mathrm{~m} / \mathrm{s}^{2}$ for 15 minutes (tables 2 and 3). A significant reduction of FBF during the recovery period was not found in either finger after the end of exposure to any other vibration stimulus (with greater acceleration magnitude for shorter duration). The Bonferroni test showed that the decrease in FBF in either finger between 30 and 45 minutes into the recovery period was significantly greater after exposure to vibration with an acceleration magnitude of either $44 \mathrm{~m} / \mathrm{s}^{2}$ for 30 minutes or $62 \mathrm{~m} / \mathrm{s}^{2}$ for 15 minutes than after exposure to any other condition, $(p<0.05)$. During recovery, there was no difference in the measures of FBF between the right (exposed) and the left (unexposed) finger within each experimental condition.

\section{Discussion}

FINGER CIRCULATION DURING VIBRATION EXPOSURE

In this study, acute exposures to $125 \mathrm{~Hz}$ vibration with any combination of acceleration magnitude and duration caused a reduction in the FBF of the vibrated finger and this reduction was significant when compared with the values of FBF before exposure. The prompt reduction of FBF in the vibrated finger at the beginning of vibration, as well as the extent of digital vasoconstriction throughout the various exposure periods, were independent of the magnitude of unweighted vibration acceleration in the range between 44 and 176 $\mathrm{m} / \mathrm{s}^{2} \mathrm{rms}$.

The immediate reaction of the digital vessels to vibration was similar to that found in our previous experimental studies where the digital circulatory effects of either acceleration magnitude or duration of exposure to a vibration frequency of $125 \mathrm{~Hz}$ were investigated separately. $^{23}$ It has been suggested that the immediate vasoconstriction in the exposed finger is mediated by a vibration induced neurogenic reflex in which the afferent branch is represented by some mechanoreceptors located in the tissues of the hand. ${ }^{78}$ Among these, the subcutaneous pacinian corpuscles are anatomically connected with sympathetic nervous fibres, ${ }^{15}$ and microneurographical investigations have shown that they are highly sensitive to vibration stimuli in the frequency region $63-500 \mathrm{~Hz} .{ }^{16}$ In this study, a reduction of FBF during exposure to vibration was also found in the contralateral (non-vibrated) finger. This finding is consistent with the results of other experimental studies which found that vibration can give rise to vasoconstrictive effects in anatomical areas distant from the site of application of the mechanical stimulus. With 
a photoelectric plethysmographic technique, Färkillä and Pyykkö found that unilateral vibration with frequencies of 60 and $100 \mathrm{~Hz}$ were the most effective in causing vasospasm in the contralateral (non-vibrated) hands of professional lumberjacks who operated chain saws. ${ }^{8}$ Egan et al reported that vibration generated by a pneumatic chisel and applied to the right hand of healthy male volunteers was associated with a significant bilateral reduction in finger and toe blood flow and a significant increase in heart rate. ${ }^{17}$ With a microneurographical technique, Japanese authors found that exposure to vibration of one hand triggered sympathetic activity in either the median nerve of the contralateral upper limb or the tibial nerve of the lower limbs. ${ }^{18} 19$ The increased discharge from the sympathetic nerve fibres caused a significant reduction of blood flow in the innervation zones. The results of these studies, as well as the finding that vibration induced digital vasoconstriction is abolished by digital nerve blockade, ${ }^{20}$ suggest that a central sympathetic reflex mechanism may be operative during exposure to hand transmitted vibration. Vibration could induce an increased activity of the peripheral mechanoreceptors in the fingers and hands which results in an excessive efferent sympathetic outflow causing digital vasoconstriction. However, the findings of the present investigation seem also to suggest the possible intervention of other vasoconstrictor mechanisms, perhaps of local origin, during vibration because the reduction of $\mathrm{FBF}$ in the vibrated finger was significantly stronger than that found in the contralateral (non-vibrated) finger.

FINGER CIRCULATION AFTER VIBRATION

The response of finger circulation to the end of exposures to vibration was characterised by a prompt increase in $\mathrm{FBF}$ which was more pronounced in the ipsilateral than in the contralateral finger. The pathophysiological mechanisms underlying these immediate circulatory effects after vibration are still unclear. Investigators have provided several interpretations - such as a transitory impairment of myogenic or neurogenic vasoregulatory functions in the digital arterioles and arteries, a release of local vasodilatory factors of endothelial origin, or a diminished discharge of vasoconstrictor bursts from the sympathetic nervous system to the digital vessels owing to the abolition of vibration induced hyperactivity from the afferent mechanoreceptors in the fingers and hands. ${ }^{20-22}$

In this study, acute exposures to different combinations of vibration magnitude and duration, all with the same energy equivalent acceleration magnitude, were associated with different patterns in recovery of FBF in both the vibrated and the non-vibrated finger. We found a progressive decrease in the FBF of both fingers during the second half of the recovery period after exposure to vibration with acceleration magnitudes of $44 \mathrm{~m} / \mathrm{s}^{2}$ for 30 minutes and $62 \mathrm{~m} / \mathrm{s}^{2}$ for 15 minutes. Significant vasoconstrictor after effects were not found in either finger after exposure to any of the other vibration stimuli with greater acceleration magnitudes for shorter durations. This finding is consistent with the results of our previous study of the changes in finger circulation after different durations of exposure to unilateral vibration with a frequency of $125 \mathrm{~Hz}$ and a constant acceleration magnitude of $87 \mathrm{~m} / \mathrm{s}^{2}$ rms: it was found that the longer the duration of exposure to vibration in the range 7.5-30 minutes, the stronger the vasoconstriction during recovery in both an ipsilateral and a contralateral finger. ${ }^{2}$ Other experimental studies have provided evidence for the existence of vibration after effects in both animal preparations and the human finger. ${ }^{23}{ }^{24}$ In a study of in vivo stimulation of rat femoral arteries with a vibration of $50 \mathrm{~Hz}$ and $0.3 \mathrm{~mm}$ displacement, Azuma et al found that the responsiveness of the arteries to noradrenaline (norepinephrine) increased with an increase in the duration of vibration stimulation. ${ }^{23}$ Moreover, the arterial hyperresponsiveness to noradrenaline persisted longer after the end of vibration as the duration of the applied stimulus increased from 1 to 6 hours. This finding is similar to the present finding of greater vibration after effects after longer durations of exposure. Investigating the circulatory effects of a unilateral 30 minute exposure to hand transmitted vibration in healthy men, Olsen reported an exaggerated vasoconstrictor response to cold in fingers of both hands 60 minutes after the end of the vibration. ${ }^{24}$ According to this author, vibration can induce either a hyperactivity of the central sympathetic nervous system or the release of circulating vasopressor agents. Such pathophysiological mechanisms could provide an explanation for the bilateral occurrence of digital vasoconstrictor effects after the end of exposure to unilateral vibration, as found in the present investigation.

Both intrinsic (local) and extrinsic (neural or endocrine) vasoregulatory mechanisms are thought to be involved in the pathogenesis of vibration induced digital vasospastic disorders. ${ }^{20}{ }^{22} \mathrm{~A}$ dominant role for centrally mediated vasomotor mechanisms during an attack of Raynaud's phenomenon has been suggested. ${ }^{22}$ Among local factors, a possible role for endothelial derived contracting factors, such as endothelin-1, has been argued in experimental and epidemiological investigations of vibration induced white finger. ${ }^{25} 26$ Endothelin-1 is a potent and long lasting vasoconstrictor peptide that has been found to increase in chain saw operators after 5 minute exposures to vibration of $120 \mathrm{~Hz}$ with an unweighted acceleration of $50 \mathrm{~m} / \mathrm{s}^{2} \mathrm{rms} .{ }^{25} \mathrm{In}$ both animal and human arteries, endothelin-1 can amplify contractions evoked by either vasoactive hormones or neurotransmitters released from adrenergic nerve endings. ${ }^{27}$ It is probable that vibration induced vasoconstrictor after effects are the result of a complex interaction between vasomotor activities mediated through pathophysiological mechanisms of endogenous (local vasoactive substances) and exogenous (sympathetic adrenergic nerves) origin. 
ENERGY EQUIVALENT TIME DEPENDENCY FOR EXPOSURE TO VIBRATION

The concept of energy equivalence implies that an increase in the magnitude of vibration can be offset by a reduction in the duration of exposure: in fact a doubling of magnitude (a) would require a fourfold reduction of duration (t) - that is, $a^{2} t=$ constant. This is used in various standards to define a time dependency for daily exposures so that workers are exposed to shorter durations of vibration if the magnitude is high. ${ }^{56}$

Our present and past results show that the vasoconstriction occurring during vibration is independent of the duration of exposure (for durations up to 30 minutes). ${ }^{2}$ Although vasoconstriction during exposure is dependent on vibration magnitude, ${ }^{3}$ it does not change significantly with increasing duration of exposure and so it cannot be well predicted by an energy equivalent time dependence. However, our present and past results also show that the vasoconstriction that follows exposure to vibration depends on the exposure duration, as well as the frequency and magnitude of the vibration. ${ }^{2-4}$ The five energy equivalent conditions in the present study did not produce the same vasoconstriction after exposure. It seems that the exposure duration had a greater effect than predicted by energy equivalence, so the longer exposures (with the lower magnitudes of vibration) caused the greatest vasoconstriction. This finding was obtained with $125 \mathrm{~Hz}$ vibration at magnitudes from 44 to $176 \mathrm{~m} / \mathrm{s}^{2}$ $\mathrm{rms}\left(5.5-22 \mathrm{~m} / \mathrm{s}^{2} \mathrm{rms}\right.$ weighted) and may not apply with lower magnitudes.

With $125 \mathrm{~Hz}$ vibration, in previous studies we have separately investigated the vasoreaction to varying durations of exposure (7.5-30 minutes at $87 \mathrm{~m} / \mathrm{s}^{2} \mathrm{rms}$ ) and varying magnitudes of vibration $\left(5.5-62 \mathrm{~m} / \mathrm{s}^{2} \mathrm{rms}\right.$ for 15 minutes). ${ }^{23}$ Although a fourfold increase in duration had, at most, a small effect on FBF during exposure, it greatly reduced the minimum FBF after exposure (reduced from about $75 \%$ to $25 \%$ of $\mathrm{FBF}$ before exposure). ${ }^{2} \mathrm{By}$ contrast, an 11-fold increase in vibration magnitude roughly halved the minimum FBF during exposure and also after exposure. ${ }^{3}$ Clearly, one simple relation between vibration duration and magnitude will not fit both FBF changes during exposure and those after exposure. It seems that vibration magnitude may be sufficient to roughly predict changes in $\mathrm{FBF}$ during vibration between 5.5 and $87 \mathrm{~m} / \mathrm{s}^{2}$ rms. Changes in FBF after exposure are affected by both the magnitude and the duration of exposure, but if there are proportionate changes in both duration and magnitude, the changes in duration have the greater effect. This is contrary to an energy time dependency where changes in magnitude have a greater effect than similar percentage changes in duration of exposure.

Our investigations confirm that the vascular responses to hand transmitted vibration are complex. $^{2-4912}$ Predictions of the severity of occupational exposures to vibration require knowledge of the effects of varying combinations of duration and magnitude of exposure.
Further systematic exploration of the separate and combined effects of these and other variables-for example, vibration frequency and direction-is required to allow such predictions.

This research was supported by the European Commission 3251(Vibration Injury Network).

1 Griffin MJ. Handbook of human vibration. London: Academic Press, 1990.

2 Bovenzi M, Lindsell CJ, Griffin MJ. Duration of acute exposures to vibration and finger circulation. Scand 7 Work Environ Health 1998;24:130-7.

3 Bovenzi M, Lindsell CJ, Griffin MJ. Magnitude of acute exposures to vibration and finger circulation. Scand $\mathcal{F}$ Work Environ Health 1999;25:278-84

4 Bovenzi M, Lindsell CJ, Griffin MJ. Acute vascular response to the frequency of vibration transmitted to the hand. Occup Environ Med 2000;57:422-30.

5 International Organization for Standardization. Mechanical vibration. Guidelines for the measurement and the assessment of human exposur

6 British Standards Institution. Measurement and evaluation of human exposure to vibration transmitted to the hand. London: BSI, 1987:6842.

7 Hyvärinen J, Pyykkö I, Sundberg S. Vibration frequencies and amplitudes in the etiology of traumatic vasospastic disease. Lancet 1973;i:791-4.

8 Färkillä M, Pyykkö I. Blood flow in the contralateral hand during vibration and hand grip contractions of lumberjacks. Scand $\mathcal{F}$ Work Environ Health 1979;5:368-74.

9 Bovenzi M, Griffin MJ. Haemodynamic changes in ipsilateral and contralateral fingers caused by acute exposures to hand transmitted vibration. Occup Environ Med 1997;54:566-76.

10 Greenfield ADM, Whitney RJ, Mowbray JF. Methods for the investigation of peripheral blood flow. Br Med Bull 1963;19:101-9.

11 Nielsen SL, Bell G, Lassen NA. Strain gauge studies of distal blood pressure in normal subjects and in patients with peripheral arterial disease. Analysis of normal variation and reproducibility and comparison to intraartierial measurements. Scand f Clin Lab Invest 1973;31 (suppl 128):103-9.

12 Bovenzi M, Griffin MJ, Ruffell CM. Acute effects of vibration on digital circulatory function in healthy men. Occup Environ Med 1995;52:834-41.

13 Greenhouse SW, Geisser S. On methods in the analysis of profile data. Psychometrika 1959;24:95-111.

14 Diggle PJ, Liang KY, Zeger SL. Analysis of longitudinal data. Oxford: Oxford University Press, 1994. (Oxford Statistical Science Series No 13.)

15 Santini M, Ibata Y, Pappas D. The fine structure of the sympathetic axon within the Pacinian corpuscle. Brain Res 1971;33:279-87.

16 Lundström R. Responses of mechanoreceptive afferent units in the glabrous skin of the human hand to vibration. Scand 7 Work Environ Health 1986;12:413-6.

17 Egan CE, Espie BH, McGrann S, et al. Acute effects of vibration on peripheral blood flow in healthy subjects. Occup Environ Med 1996;53:663-9.

18 Okada A, Naito M, Ariizumi M, et al. Experimental studies on the effects of vibration and noise on sympathetic nerve activity in skin. Eur $\mathcal{F}$ Appl Physiol 1991;62:324-31.

19 Sakakibara H, Iwase S, Mano T, et al. Skin sympathetic activity in the tibial nerve triggered by vibration applied to the hand. Int Arch Occup Environ Health 1990;62:455-8.

20 Greenstein D, Kester D. Acute vibration: its effect on digital blood flow by central and local mechanisms. Proceedings of the Institute of Mechanical Engineers (Part H) 1992,206.105-

Olsen N, Petring OU, Rossing N. Transitory postural vasomotor dysfunction in the finger after short term hand
vibration. Br f Ind Med 1989;46:575-81.

Olsen N. Centrally and locally mediated vasomotor activities in Raynaud's phenomenon. Scand $\mathcal{F}$ Work Environ Health 1987;13:309-12.

23 Azuma T, Ohhashi T, Sakaguchi K. Vibration-induced hyperresponsiveness of arterial smooth muscle to adrenaline with special reference to Raynaud's phenomenon in vibration disease. Cardiovasc Res 1978;12:758-64.

24 Olsen N. Vibration after effects on vasoconstrictor response to cold in the normal finger. Eur f Appl Physiol 1993;66:246-8

25 Yoshida M, Nakamura H, Okazawa T, et al. Response of plasma platelet-derived growth factor (PDGF) and endothelin to vibration exposure in chain-sawyers. In: Gemne G, Brammer AJ, Hagberg M, et al, eds. Proceedings of Stockholm Workshop 94. Hand-arm vibration syndrome: diagnostics and quantitative relationships to exposure. Solna: National Institute of Occupational Health, Arbete och Hälsa 1995;5:171-8.

26 Palmer KT, Mason H. Serum endothelin concentrations in workers exposed to vibration. Occup Environ Med 1996;53: 118-24.

27 Yang Z, Richard V, von Segesser L, et al. Threshold concentrations of endothelin-1 potentiate contractions to norepinephrine and serotonin in human arteries. A new mechanism of vasospasm? Circulation 1990;82:188-95. 